\title{
Pesquisa em tecnologias digitais e recursos didáticos manipuláveis em Educação Matemática Inclusiva nos Anais do I ENEMI
}

Resumo: O escopo deste artigo é identificar e analisar a utilização de tecnologias digitais e recursos didáticos manipuláveis em comunicações científicas, nos Anais do I Encontro Nacional de Educação Matemática Inclusiva (ENEMI) de 2019. É um estudo de abordagem descritiva em relação aos objetivos e qualitativa quanto à análise dos dados. A pesquisa bibliográfica norteia a produção, e a Análise de Conteúdo a análise dos dados que constituem o corpus da pesquisa. O universo da investigação abrange 20 artigos, após filtragem pelos critérios de inclusão e exclusão. Os resultados apontam que professores utilizaram tecnologias digitais e recursos didáticos manipuláveis na prática pedagógica inclusiva, adaptando-os ou criando-os segundo suas próprias crenças, concepções e experiências, interpretando as intenções ao desenvolver conteúdo matemático para todos os estudantes. As categorias geradas identificam o protagonismo da educação matemática para estudantes com déficit cognitivo, deficiência visual, surdos, autistas e transtorno de déficit de atenção e hiperatividade.

Palavras-chave: Tecnologias Digitais. Recursos Didáticos Manipuláveis. Educação Matemática Inclusiva. ENEMI.

\section{Research in digital technologies and manipulable didactic resources on Inclusive Mathematics Education in the Proceedings of I ENEMI}

Abstract: The scope of this article is to identify and analyze the use of digital technologies and manipulative teaching resources in scientific communications in the Proceedings of the 1st National Meeting of Inclusive Mathematical Education (ENEMI) of 2019. It is a study with a descriptive approach concerning the objectives and qualitative as data analysis. Bibliographic research guides the production and Content Analysis guides the data analysis that make up the research corpus. The research universe comprises 20 articles, after being filtered by the inclusion and exclusion criteria. The results show that teachers used digital technologies and manipulative teaching resources in inclusive pedagogical practice, adapting or creating them according to their own beliefs, concepts, and experiences, interpreting the intentions when developing mathematical content for all students. The categories generated identify the role of mathematics education for students 
with cognitive impairment, visual impairment, the deaf, autistic, and attention deficit hyperactivity disorder.

Keywords: Digital Technologies. Manipulable Teaching Resources. Inclusive Mathematics Education. ENEMI.

\section{Investigación en tecnologías digitales y recursos didácticos manipulables en Educación Matemática Inclusiva en los Anales del I ENEMI}

Resumen: El alcance de este artículo es identificar y analizar el uso de tecnologías digitales y recursos didácticos manipulativos en comunicación científica, en Actas del I Encuentro Nacional de Educación Matemática Inclusiva (ENEMI) de 2019. Es un estudio con enfoque descriptivo en relación con objetivos y cualitativos como análisis de datos. La investigación bibliográfica orienta la producción y el análisis de contenido el análisis de datos que conforman el corpus de investigación. Ese universo comprende 20 artículos, luego de ser filtrados por criterios de inclusión y exclusión. Los resultados muestran que docentes utilizaron tecnologías digitales y recursos didácticos manipuladores en la práctica pedagógica inclusiva, adaptándolos o creándolos según sus propias creencias, conceptos y experiencias, interpretando las intenciones al desarrollar contenidos matemáticos para todos estudiantes. Las categorías generadas identifican el papel de educación matemática para estudiantes con discapacidad cognitiva, discapacidad visual, sordos, autistas y trastorno por déficit de atención e hiperactividad.

Palabra clave: Tecnologías Digitales. Recursos Didácticos Manipulables. Educación Matemática Inclusiva. ENEMI.

\section{Introdução}

A utilização da palavra tecnologia vem sendo ampliada e discutida em diversas áreas do conhecimento no meio acadêmico, na mídia e nos currículos, o que pode estar ocasionando alteração do seu significado e distanciando-se da conceituação tradicional.

Ao observar diferentes conceituações na literatura, julgamos oportuno caracterizar o significado da palavra tecnologia utilizado neste artigo, como um corpo de conhecimentos e princípios científicos que se aplicam ao planejamento, à construção e à utilização de equipamentos, processos, recursos e serviços em um determinado tipo de prática. Neste sentido, a linguagem, a escrita, os números e o pensamento podem ser considerados tecnologia (KENSKI, 2012).

Acrescentamos o termo digitais para demarcar que tecnologias digitais entendidas aqui como equipamentos, softwares educacionais ou não, aplicativos online, ambientes virtuais de aprendizagem, jogos e afins — possam ser empregadas em práticas 
pedagógicas ${ }^{1}$, concebidas e aplicadas na/para resolução ou minimização dos problemas funcionais por todos os estudantes, bem como contribuir para o aprimoramento dos processos de ensino e de aprendizagem na Educação, na Educação Matemática e na Educação Matemática Inclusiva. Como referido por Ramirez e Masutti (2009, p. 9), “é importante destacar que a tecnologia aliada às necessidades que emergem dos contextos sociais se torna produtiva no processo de transformação das relações sociais de exclusão".

Concebemos recursos didáticos manipuláveis como sendo todos recursos e quaisquer instrumentos que possam ser úteis aos processos de ensino e de aprendizagem, a exemplo de jogos, material dourado, multiplano, tangram, soroban, dentre outros, produzidos ou adaptados pelos próprios professores, que tenham objetivo didático conforme as necessidades dos estudantes, isto é, que potencializem o estabelecimento de relações entre professor, estudante e conhecimento (LORENZATO, 2010).

Diante disso, da definição de tecnologias digitais e do entendimento acerca de recursos didáticos manipuláveis, focamos a discussão sobre o uso das tecnologias digitais e recursos didáticos manipuláveis na Educação Matemática, especificamente na Educação Matemática Inclusiva. Silva et al. (2017) argumentam que o uso de tecnologias digitais por professores, na perspectiva inclusiva, tem o intuito de contribuir com os processos de ensino e de aprendizagem dos estudantes com dificuldades de acesso a um determinado conteúdo ou conceito matemático que a escola oferece.

Nesse sentido, Goedert e Borges (2016) afirmam que as atividades potencialmente didático-metodológicas, em diferentes contextos inclusivos mediados por tecnologias digitais, devem favorecer, dentre outros aspectos, o exercício cognitivo, a aproximação entre os sujeitos e o desenvolvimento de habilidades comunicativas por todos os estudantes na sala de aula. Com isso, acreditamos que tais tecnologias "podem servir como motivação aos discentes, trazendo maior interesse pela disciplina lecionada e, consequentemente, propiciando a compreensão dos conteúdos abordados pelos professores" (SOUZA e QUEIRÓS, 2019, p. 166), criando possibilidades de superação de obstáculos nos processos de ensino e de aprendizagem. Dito de outra forma, as

\footnotetext{
${ }^{1}$ Neste estudo, consideramos prática pedagógica como a relação social que pode ocorrer entre pais e filhos, professores e estudantes, advogado e cliente, médico e paciente, objetos/coisas, dentre outros, como definido por Bernstein (1990). Acrescentamos a palavra 'inclusiva' para denotar as relações sociais estabelecidas no ambiente de sala de aula, entre professor e estudantes com deficiência.
} 
tecnologias digitais possibilitam o desenvolvimento do conteúdo matemático de maneira dinâmica, divertida e interativa, contribuindo assim para a motivação dos estudantes frente ao conteúdo, constituindo-se em mais um recurso a ser utilizado para a aprendizagem e à resolução de problemas, por meio da interatividade com o conteúdo (CARVALHO, CASTRO FILHO e FERREIRA, 2017; MOURA e LAVPR, 2021).

Além disso, o processo de construção, adaptação, análise e implementação de tecnologias digitais deve estar relacionado ao contexto em que está inserida a situação de aprendizagem do estudante com deficiência, e da formação que o professor possui para introduzir, produzir ou adaptar as tecnologias digitais em sua prática pedagógica que se propõe inclusiva (SOUZA e QUEIRÓS, 2019), o que nos leva a inferir que as tecnologias digitais só se tornarão ferramentas de aprendizagem quando "seu uso estiver norteado por uma abordagem de educação que considere o desenvolvimento da autonomia do aprendiz" (BALADELI, 2009, p. 18). O interesse em compreender o uso das tecnologias digitais e os recursos didáticos manipuláveis, ligados ao ensino e à aprendizagem da Matemática, em uma perspectiva inclusiva, têm levado pesquisadores da Educação Matemática e Educação Matemática Inclusiva, e até mesmo de outras áreas, a se dedicarem a essa temática. A escolha pelo tema em questão se deve ao relevante papel que esta desempenha na formação do estudante incluso no ambiente escolar.

A relevância da presente investigação repousa em, a partir do que já foi produzido na literatura vigente, permitir um vislumbre do estado atual da pesquisa para subsidiar a discussão e, então, estabelecer um panorama em relação a duas categorias: a que considera a adaptação e a que se refere à criação de tecnologias digitais e recursos didáticos manipuláveis para o ensino de Matemática em uma perspectiva inclusiva. Neste sentido, a presente pesquisa se propôs identificar e analisar as temáticas que utilizam tecnologias digitais e recursos didáticos manipuláveis nas comunicações científicas, nos Anais do I Encontro Nacional de Educação Matemática Inclusiva (I ENEMI) realizado em 2019 - um evento nacional já iniciado com grande visibilidade no que se refere à Educação Matemática Inclusiva, promovido pelos pesquisadores do Grupo de Trabalho 13 (GT13): Diferença, Inclusão e Educação Matemática, filiados à Sociedade Brasileira de Educação Matemática (SBEM).

Este artigo segue assim organizado: a Seção 2 contempla os procedimentos 
metodológicos; na Seção 3 discutem-se os resultados; e na Seção 4 são apresentadas as considerações finais.

\section{Procedimentos metodológicos}

A base de dados utilizada para constituir o corpus desta pesquisa são comunicações científicas publicadas nos Anais do I ENEMI, que estão disponibilizadas no formato digital para consulta online.

Os resultados aqui apresentados têm por base um estudo de abordagem qualitativa, ao considerar que o intuito da investigação é analisar os significados, ou seja, os aspectos qualitativos de um tema em questão formado pela interpretação, a partir da análise dos pesquisadores, já que

\footnotetext{
a Pesquisa Qualitativa é uma pesquisa que não tem por objetivo imediato a generalização dos resultados obtidos. Nesse tipo de pesquisa, estamos interessados em levantar quais são as possíveis causas do evento observado pelo pesquisador [...]. Ela tem um caráter exploratório, no sentido de que fazemos um mapeamento do terreno estudado, visando à sua descrição detalhada (ROSA, 2013, p. 41).
}

Por isso, como o presente estudo se preocupa em gerar compreensões teóricas a respeito do uso de tecnologias digitais e recursos didáticos manipuláveis por professores que ensinam Matemática, durante a prática pedagógica de caráter inclusivo, tal método qualitativo mostrou-se mais adequado, já que o objeto da investigação e o objetivo da pesquisa requerem análise descritiva e interpretativa, ao invés de uma quantificação dos dados. Como modalidade para esta investigação, utilizamos os procedimentos técnicos da pesquisa bibliográfica em função de sua coerência com os objetivos propostos neste estudo.

A pesquisa bibliográfica é desenvolvida com base em material já elaborado, constituído principalmente de livros e artigos científicos. Embora em quase todos os estudos seja exigido algum tipo de trabalho dessa natureza, há pesquisas desenvolvidas exclusivamente a partir de fontes bibliográficas (GIL, 2007, p. 44).

O procedimento metodológico seguiu os preceitos das etapas de desenvolvimento de uma pesquisa bibliográfica apontados por Gil (2007), a saber: escolha do tema, identificação e localização das fontes, recolha do material, leitura do material utilizando a estratégia de confecção das fichas e, por fim, redação do trabalho em sintonia com o 
objetivo proposto.

Para determinar o corpus de análise da pesquisa bibliográfica, identificamos, por meio do resumo e das palavras-chave, trabalhos que abordam a temática. Em seguida, verificamos aqueles que não foram possíveis de serem identificados por meio desses dois critérios, passando à leitura na íntegra; ao todo, foram analisados 74 trabalhos. Para a composição do corpus, como critérios de inclusão, elegemos somente os textos que tratavam especificamente de trabalhos empíricos das comunicações científicas no uso das tecnologias digitais e recursos didáticos manipuláveis, na prática pedagógica que se propõe inclusiva. Nesse sentido, os critérios de exclusão permearam os trabalhos que traziam pesquisas apenas teóricas, bibliográficas, as quais se desdobram em síntese de literatura e ensaio teórico. Após definirmos como critérios de exclusão e inclusão, restaram 20 trabalhos que abordam, de forma explícita, a adoção de tecnologias digitais e recursos didáticos manipuláveis na perspectiva inclusiva no ensino de Matemática.

Após a seleção dos trabalhos que estavam em consonância com o objetivo deste estudo e que traziam a análise de uma prática pedagógica inclusiva, organizamos os dados em uma planilha no software Excel - tema abordado; tipo de tecnologia utilizado; conteúdo/conceito matemático e fundamentos teórico-metodológicos para posterior tabulação dos itens. O Quadro 1 traz a relação dos trabalhos selecionados, contendo os títulos, os autores, o conceito/conteúdo matemático e a respectiva tecnologia digital/recurso didático utilizado pelo professor ${ }^{2}$.

Quadro 1: Títulos e autores dos trabalhos selecionados para o corpus

\begin{tabular}{|c|l|c|c|c|}
\hline Código & \multicolumn{1}{|c|}{ Título } & \multicolumn{1}{|c|}{ Autor(es) } & $\begin{array}{c}\text { Conceito/Conteúdo } \\
\text { Matemático }\end{array}$ & Objeto de Estudo \\
\hline T1 & $\begin{array}{l}\text { O uso do soroban como recurso de } \\
\text { perspectiva inclusiva: relato de } \\
\text { experiência numa turma regular em } \\
\text { que alunos deficientes visuais são } \\
\text { protagonistas. }\end{array}$ & $\begin{array}{l}\text { Wagner Rohr Garcez; } \\
\text { Regina Lucia Silveira } \\
\text { Martins; Regina Kátia } \\
\text { Cerqueira Ribeiro }\end{array}$ & Números Naturais & $\begin{array}{c}\text { Recursos Didáticos } \\
\text { Manipuláveis }\end{array}$ \\
\hline T2 & $\begin{array}{l}\text { O jogo tangram no processo de ensino } \\
\text { e de aprendizagem de matemática com } \\
\text { estudantes com deficiência intelectual } \\
\text { na perspectiva de resolução de } \\
\text { problemas. }\end{array}$ & $\begin{array}{c}\text { Débora Resende Pereira } \\
\text { Barbosa; Rosana Maria } \\
\text { Mendes }\end{array}$ & $\begin{array}{c}\text { Conceitos } \\
\text { Geométricos }\end{array}$ & $\begin{array}{c}\text { Recursos Didáticos } \\
\text { Manipuláveis }\end{array}$ \\
\hline T3 & $\begin{array}{l}\text { Tampimática e o pensamento } \\
\text { aritmético: um estudo de quantificação } \\
\text { com um estudante com deficiência } \\
\text { intelectual no Proeja. }\end{array}$ & $\begin{array}{l}\text { Elcio Pasolini Milli; } \\
\text { Edmar Reis Thiengo }\end{array}$ & $\begin{array}{l}\text { Conceitos Aritméticos } \\
\text { Recursos Didáticos } \\
\text { Manipuláveis }\end{array}$ \\
\hline
\end{tabular}

2 Todos os trabalhos podem ser consultados em sua íntegra nos anais do I ENEMI, disponível em http://eventos.sbem.com.br/index.php/GT-13/ENEMI2019/schedConf/presentations 


\begin{tabular}{|c|c|c|c|c|}
\hline $\mathrm{T} 4$ & $\begin{array}{l}\text { A plataforma Khan Academy para o } \\
\text { ensino e aprendizagem da matemática } \\
\text { por alunos com TDAH. }\end{array}$ & $\begin{array}{c}\text { Alexandre Matias Russo; } \\
\text { Celina Aparecida Almeida } \\
\text { Pereira Abar }\end{array}$ & Função & Tecnologia Digital \\
\hline $\mathrm{T} 5$ & $\begin{array}{l}\text { Apropriação do conceito de números } \\
\text { por um estudante com Síndrome de } \\
\text { Williams a partir do Conceito de } \\
\text { Compensação de Vygotsky. }\end{array}$ & $\begin{array}{c}\text { Flavia Fassarella Cola dos } \\
\text { Santos; Edmar Reis } \\
\text { Thiengo }\end{array}$ & Conceito de números & $\begin{array}{l}\text { Recursos Didáticos } \\
\text { Manipuláveis }\end{array}$ \\
\hline T6 & $\begin{array}{l}\text { Tecnologia assistiva para o ensino do } \\
\text { campo multiplicativo para autistas. }\end{array}$ & $\begin{array}{l}\text { Jéssica Maria Oliveira de } \\
\text { Luna; Agnaldo } \\
\text { Esquincalha }\end{array}$ & $\begin{array}{l}\text { Estrutura } \\
\text { multiplicativa }\end{array}$ & Tecnologia Digital \\
\hline $\mathrm{T} 7$ & $\begin{array}{l}\text { Construção de materiais pedagógicos } \\
\text { para o ensino de matemática de alunos } \\
\text { surdos. }\end{array}$ & $\begin{array}{c}\text { Kelvia Nunes da Silva; } \\
\text { Walber Christiano Lima } \\
\text { da Costa }\end{array}$ & --- & $\begin{array}{l}\text { Recursos Didáticos } \\
\text { Manipuláveis }\end{array}$ \\
\hline $\mathrm{T} 8$ & $\begin{array}{l}\text { Análise do registro das atividades } \\
\text { matemáticas para estudantes cegos: da } \\
\text { tinta ao Braille. }\end{array}$ & $\begin{array}{l}\text { Karen Valencia Mercado; } \\
\text { Ivete Baraldi }\end{array}$ & --- & Tecnologia Digital \\
\hline T9 & $\begin{array}{l}\text { Estudantes surdos e a construção da } \\
\text { noção de tempo: estratégias de ensino } \\
\text { em contexto bilíngue (Libras/Língua } \\
\text { Portuguesa). }\end{array}$ & $\begin{array}{l}\text { Silene Pereira Madalena; } \\
\text { Caroline Lima de Souza }\end{array}$ & Noção de tempo & $\begin{array}{l}\text { Recursos Didáticos } \\
\text { Manipuláveis }\end{array}$ \\
\hline $\mathrm{T} 10$ & $\begin{array}{l}\text { Um cenário de aprendizagem de } \\
\text { probabilidade: uma possibilidade para } \\
\text { alunos com deficiência visual. }\end{array}$ & $\begin{array}{l}\text { Jaqueline Lixandrão } \\
\text { Santos; Rute Elizabete de } \\
\text { Souza Rosa Borba }\end{array}$ & $\begin{array}{l}\text { Conceito de } \\
\text { Probabilidade }\end{array}$ & $\begin{array}{l}\text { Recursos Didáticos } \\
\text { Manipuláveis }\end{array}$ \\
\hline T11 & $\begin{array}{l}\text { Tangram: uma proposta para o ensino } \\
\text { de porcentagem a alunos com } \\
\text { deficiência intelectual. }\end{array}$ & $\begin{array}{l}\text { Rosângela Pimenta de } \\
\text { Sousa; Alcione Marques } \\
\text { Fernandes }\end{array}$ & Porcentagem & $\begin{array}{l}\text { Recursos Didáticos } \\
\text { Manipuláveis }\end{array}$ \\
\hline $\mathrm{T} 12$ & $\begin{array}{l}\text { Uma experiência com o GeoGebra } \\
\text { utilizando dispositivos móveis } \\
\text { envolvendo alunos do } 8^{\circ} \text { ano em } \\
\text { condições especiais. }\end{array}$ & $\begin{array}{l}\text { Talita Araújo Salgado } \\
\text { Alvarez Faustino }\end{array}$ & $\begin{array}{c}\text { Conceitos } \\
\text { Geométricos }\end{array}$ & Tecnologia Digital \\
\hline T13 & $\begin{array}{l}\text { A experiência de utilizar o soroban e o } \\
\text { material dourado no ensino de } \\
\text { matemática a um estudante cego. }\end{array}$ & $\begin{array}{l}\text { Adrielly Antonia Santos } \\
\text { Gomes; Franciana } \\
\text { Teixeira Franco Ribeiro; } \\
\text { Rosana Maria Mendes }\end{array}$ & Adição e Subtração & $\begin{array}{l}\text { Recursos Didáticos } \\
\text { Manipuláveis }\end{array}$ \\
\hline T14 & $\begin{array}{l}\text { Experiências na educação matemática } \\
\text { vinculadas à surdocegueira. }\end{array}$ & $\begin{array}{l}\text { Heniane Passos Aleixo; } \\
\text { Thaís Philipsen } \\
\text { Grützmann }\end{array}$ & Conceito de Números & $\begin{array}{l}\text { Recursos Didáticos } \\
\text { Manipuláveis }\end{array}$ \\
\hline T15 & $\begin{array}{l}\text { Vendando alunos videntes para um } \\
\text { mergulho na matemática combinatória } \\
\text { inclusiva. }\end{array}$ & $\begin{array}{l}\text { André Martins Pinto } \\
\text { Ferreira Alves; Ágatha } \\
\text { Cristina de Almeida } \\
\text { Santos; Marcelo Almeida } \\
\text { Bairral }\end{array}$ & Análise Combinatória & $\begin{array}{l}\text { Recursos Didáticos } \\
\text { Manipuláveis }\end{array}$ \\
\hline T16 & $\begin{array}{l}\text { O uso de tecnologias assistivas no } \\
\text { ensino de matemática para alunos com } \\
\text { deficiência visual no ensino superior. }\end{array}$ & $\begin{array}{l}\text { Mariane de Almeida da } \\
\text { Silva; Claudia Segadas } \\
\text { Vianna }\end{array}$ & Cálculo I & Tecnologia Digital \\
\hline T17 & $\begin{array}{l}\text { Reflexões sobre a metodologia e o uso } \\
\text { de materiais grafotáteis no ensino de } \\
\text { trigonometria em um contexto } \\
\text { inclusivo. }\end{array}$ & Claudio Mendes Dias & Trigonometria & $\begin{array}{l}\text { Recursos Didáticos } \\
\text { Manipuláveis }\end{array}$ \\
\hline T18 & $\begin{array}{l}\text { Uma parceria universidade-escola: } \\
\text { atividades em Sala de Recursos } \\
\text { Multifuncionais. }\end{array}$ & $\begin{array}{l}\text { Vanessa Barreto da Silva; } \\
\text { Jeanne Denise Bezerra de } \\
\text { Barros }\end{array}$ & $\begin{array}{l}\text { Plano Cartesiano } \\
\text { Fração } \\
\text { Estatística }\end{array}$ & $\begin{array}{l}\text { Recursos Didáticos } \\
\text { Manipuláveis }\end{array}$ \\
\hline T19 & $\begin{array}{l}\text { Uma estudante cega e a aprendizagem } \\
\text { em matemática: apontamentos } \\
\text { semiocognitivos no acesso aos objetos } \\
\text { de saber. }\end{array}$ & $\begin{array}{c}\text { Daiana Zanelato dos } \\
\text { Anjos; Méricles Thadeu } \\
\text { Moretti }\end{array}$ & Expressões Algébricas & Tecnologia Digital \\
\hline $\mathrm{T} 20$ & $\begin{array}{l}\text { Interpretação de gráficos por } \\
\text { estudantes cegos: reflexões sobre o uso } \\
\text { de tecnologia assistiva. }\end{array}$ & $\begin{array}{l}\text { Mayra Darly da Silva; } \\
\text { Liliane Maria Teixeira } \\
\text { Lima de Carvalho }\end{array}$ & Estatística & $\begin{array}{l}\text { Recursos Didáticos } \\
\text { Manipuláveis }\end{array}$ \\
\hline
\end{tabular}

Fonte: Elaborado pelos Autores (2021) 
À luz dos pressupostos de Bardin (2009), decidimos realizar um recorte na técnica de análise dos dados, ou seja, optamos pela análise categorial que, de acordo com a referida literatura, "funciona por operações de desmembramento do texto em unidades, em categorias, segundo reagrupamentos analógicos" (BARDIN, 2009, p. 199).

Portanto, as categorias aqui apresentadas emergiram da análise dos dados, isto é, foram definidas no processo interpretativo, que representam elementos em comum em todo o corpus da pesquisa. Dessa forma, as duas categorias emergiram após a leitura na íntegra dos 20 textos; adaptando tecnologias digitais e recursos didáticos manipuláveis para o ensino de Matemática; e criando tecnologias digitais e recursos didáticos manipuláveis para o ensino de Matemática.

\section{Resultados e discussão dos dados}

Nesta seção, apresentamos os resultados da análise dos trabalhos selecionados nesta pesquisa bibliográfica, com ênfase em duas categorias referentes à forma como os professores utilizam tecnologias digitais e recursos didáticos manipuláveis na prática pedagógica, representados nos anais do I ENEMI, bem como suas respectivas discussões. A primeira categoria apresenta os resultados obtidos na adaptação de tecnologias digitais e recursos didáticos manipuláveis, enquanto a segunda confere detalhes sobre pesquisas que criaram tecnologias digitais e recursos didáticos manipuláveis para o ensino de Matemática.

\subsection{Tecnologias digitais e recursos didáticos manipuláveis para o ensino de Matemática na perspectiva da adaptação}

Concebemos adaptação como ajustes, modificações e estratégias diferenciadas, realizadas pelo(a) professor(a), para compreender as necessidades educacionais especiais decorrentes de deficiência apresentada pelo(a) estudante. Isso significa que promover as adaptações/adequações no uso das tecnologias digitais e recursos didáticos manipuláveis não implica reduzir ou eliminar as dificuldades relacionadas aos aspectos dos conteúdos ou conceitos matemáticos, mas ajustá-las às condições de aprendizagem do estudante com deficiência (PLETSCH, 2009).

A análise dos trabalhos selecionados possibilitou destacar duas abordagens relacionadas ao uso das tecnologias digitais e recursos didáticos manipuláveis na 
Educação Matemática Inclusiva, a saber: a) estratégias pedagógicas para o ensino de Matemática; b) recursos tecnológicos para o ensino de Matemática.

Entre os trabalhos que discutiram as estratégias pedagógicas para o ensino de Matemática, foram agrupados dez trabalhos — T1, T2, T5, T8, T11, T13, T14, T15, T17, T19 - ; entre eles, podemos exemplificar com as pesquisas desenvolvidas por Barbosa e Mendes (T2) Souza e Fernandes (T11), que utilizaram o recurso didático tangram para o ensino de Matemática a estudantes com deficiência intelectual.

Na primeira pesquisa, Barbosa e Mendes (T2) estudaram as potencialidades que o tangram oferece para a apropriação/mobilização de conceitos geométricos por estudantes com deficiência intelectual, em uma sala de aula de Matemática, conforme explicitado pelos autores: "faremos a investigação de uma experiência de ensino e aprendizagem com alunos que apresentam Deficiência Intelectual, cujas atividades serão mediadas pelo jogo Tangram e concebidas por meio da perspectiva da Educação Inclusiva" (BARBOSA e MENDES, T2, p. 5).

Souza e Fernandes (T11), por sua vez, buscaram possíveis respostas para a situação-problema: Como realizar as adaptações curriculares e as flexibilizações para alunos com Deficiência Intelectual da primeira série do Ensino Médio, usando o Tangram para o ensino das porcentagens? Os resultados do seu uso, nas atividades com estudantes com deficiência intelectual, apontaram que "após introduzir essa metodologia com o uso do tangram, os dois alunos apresentaram uma evolução considerável quanto à leitura e interpretação" (SOUZA e FERNANDES, T11, p. 5). Tais resultados foram identificados a partir do envolvimento dos estudantes com o tangram, o que contempla a construção do conhecimento por meio de ações em que os estudantes impulsionam as suas habilidades baseadas na interação da atividade potencialmente inclusiva.

Santos e Thiengo (T5) e Aleixo e Grützmann (T14) realizaram suas pesquisas abordando a construção do conceito de número. Na primeira investigação, Santos e Thiengo (T5) discutiram os mecanismos utilizados por um estudante com Síndrome de Williams para a apropriação do conceito de números, a partir do construto de compensação de Vygotsky (2010). Já Aleixo e Grützmann (T14) investigaram a construção do conceito de número por uma aluna com surdocegueira congênita. Os resultados desses dois estudos apontaram que a adaptação de recursos didáticos para 
prática pedagógica inclusiva contribuiu para os processos mentais trabalhados com estudantes com surdocegueira e Síndrome de Williams, podendo (e devendo) ser oportunizados a todos os estudantes, pois assim oferecem uma base fortalecida para a compreensão de conteúdos matemáticos. Os mesmos autores destacaram, também, que a manipulação e a execução de recursos representaram resultados positivos na apropriação do conceito de números.

Mercado e Baraldi (T8) e Anjos e Moretti (T19) utilizaram como referência a Teoria de Representações Semióticas, de Raymond Duval, para identificar e compreender os registros de estudantes com deficiência visual. Os resultados apresentados fomentam que o material em Braille parece não considerar as diferenças semiocognitivas, causando dificuldade na compreensão do conteúdo matemático. Assim como nos demais trabalhos — T1, T13, T15, T17 —, os supracitados convergem para o entendimento de que os recursos didáticos reproduzidos por professores na prática pedagógica inclusiva são relevantes para atenuar as dificuldades dos estudantes no conteúdo de Geometria e porcentagem, uma vez que possibilitam aos estudantes autonomia na construção do conhecimento.

$\mathrm{Na}$ segunda abordagem, recursos tecnológicos para o ensino de Matemática, presente nas discussões sobre adaptação de tecnologias digitais no ensino de Matemática, identificamos quatro trabalhos - T4, T6, T12, T16. Entre estes trabalhos, Faustino (T12) expôs os recursos que o GeoGebra poderia oferecer ao cenário inclusivo para aprendizagem matemática do estudo de conceitos geométricos, junto a estudantes do $8^{\circ}$ ano do Ensino Fundamental, em que estava regulamente matriculado um estudante com Transtorno de Hiperatividade e Déficit de Atenção (TDAH). Dentre os resultados, a cooperação e a autonomia dos estudantes foram os pontos de destaque apontados pelo autor, ao fazer uso do recurso tecnológico GeoGebra para criar cenários inclusivos para a aprendizagem de Matemática. Conforme explicitado por ele, "essa cooperação era visível a cada vez que um educando demonstrava dificuldade em executar uma ação, pois sempre havia um ou mais colegas para auxiliá-lo" (FAUSTINO, 2019, p. 8).

Atentos aos recursos tecnológicos para o ensino de Matemática, Russo e Abar (T4) abordaram as maneiras como o recurso da plataforma Khan Academy pode contribuir para o aprimoramento do conhecimento matemático de estudantes diagnosticados com 
TDAH. Os participantes da pesquisa foram seis estudantes regularmente matriculados no Ensino Médio e diagnosticados com TDAH. Os resultados apontaram que as interações realizadas pelos sujeitos por meio da plataforma contribuíram para a compreensão deles quanto ao conteúdo proposto. Isso reforça o argumento de que o uso pedagógico adequado dos recursos tecnológicos permite que os estudantes com TDAH tenham reais condições de aprendizagem, tanto em Matemática como em qualquer outra disciplina escolar. Isso possibilita serem os protagonistas na construção do seu conhecimento, levando ao crescimento intelectual, pessoal e profissional (SANTOS et al., 2020).

Luna e Esquincalha (T6) buscaram contribuir para o desenvolvimento do campo multiplicativo em estudantes autistas, por meio do uso do recurso tecnológico TEACCH (Treatment and Education of Autistic and Related Communication-Handicapped Children), um software que fornece aos estudantes estrutura e organização adequadas ao desenvolvimento no ambiente de aprendizagem. Para isso, os autores se apoiaram na Teoria dos Campos Conceituais, de Vergnaud, como partida para o ensino do campo multiplicativo, a fim de conhecer a maneira como o estudante constrói o conhecimento matemático e quais artifícios são usados para resolver determinado problema, possibilitando diferentes estratégias para seu ensino. Os autores ressaltaram que a lente teórica da Teoria dos Campos Conceituais funcionaria como ponto de partida para o ensino do campo multiplicativo e que o TEACCH seria o ambiente específico para aprendizagem do estudante autista.

Silva e Vianna (T16) investigaram como os recursos tecnológicos Braille Fácil, Dosvox e SonoraMat podem ou não auxiliar na compreensão conceitual de tópicos da disciplina de Cálculo I por um aluno com deficiência visual no Ensino Superior. O estudo está fundamentado nos pressupostos teórico-metodológicos de Vygotsky. As autoras concluíram que a pesquisa pode contribuir para o campo da Educação Matemática ao trazer mais uma narrativa e a possibilidade de ensino e aprendizagem do conteúdo da disciplina de Cálculo I, por meio do uso de recursos tecnológicos. Para o campo da Educação Especial, na perspectiva da Educação Inclusiva, contribui ao "evidenciar que o uso adequado de tecnologias assistivas no ensino superior pode promover e garantir um ensino e aprendizagem de qualidade, ao fazer o aluno se sentir incluído e parte deste processo (SILVA e VIANNA, T16, p. 10).

Considerando as pesquisas relacionadas às tecnologias digitais e recursos 
didáticos manipuláveis na Educação Matemática Inclusiva, indicamos, no Quadro 2, uma síntese dos trabalhos enquadrados nesta categoria, bem como as duas subcategorias temáticas.

Quadro 2: Síntese dos 14 trabalhos relacionados à primeira categoria

\begin{tabular}{|c|c|c|c|c|}
\hline Categoria & Subcategoria & Autor & Objetivo & Principais resultados \\
\hline \multirow{10}{*}{$\begin{array}{c}\text { Tecnologias } \\
\text { digitais e } \\
\text { recursos } \\
\text { didáticos } \\
\text { para o } \\
\text { ensino de } \\
\text { Matemática } \\
\text { na } \\
\text { perspectiva } \\
\text { da } \\
\text { adaptação }\end{array}$} & \multirow{10}{*}{$\begin{array}{l}\text { Estratégias } \\
\text { pedagógicas } \\
\text { para o ensino } \\
\text { de Matemática }\end{array}$} & $\begin{array}{l}\text { Barbosa e Mendes } \\
\text { (T2) }\end{array}$ & $\begin{array}{l}\text { Analisar as diferentes estratégias } \\
\text { de resolução de problemas gerados } \\
\text { pelo jogo no processo de ensino e } \\
\text { aprendizagem de } \quad \text { de conceitos } \\
\text { geométricos. }\end{array}$ & $\begin{array}{l}\text { Resultados iniciais de uma pesquisa } \\
\text { de mestrado que busca trazer uma } \\
\text { contribuição, ainda que incipiente, } \\
\text { aos estudos sobre a Educação } \\
\text { Inclusiva. }\end{array}$ \\
\hline & & $\begin{array}{l}\text { Souza e Fernandes } \\
\text { (T11) }\end{array}$ & $\begin{array}{l}\text { Selecionar práticas pedagógicas de } \\
\text { adaptação e flexibilização nos } \\
\text { conteúdos de porcentagens. }\end{array}$ & $\begin{array}{l}\text { Resultados iniciais de uma pesquisa } \\
\text { de mestrado que minimizou a } \\
\text { defasagem apresentada no conteúdo } \\
\text { matemático trabalhado. }\end{array}$ \\
\hline & & $\begin{array}{l}\text { Garcez, Martins e } \\
\text { Ribeiro (T1) }\end{array}$ & $\begin{array}{l}\text { Relatar a experiência vivenciada } \\
\text { pelos autores ao colocarem alunos } \\
\text { com deficiência visual como } \\
\text { protagonistas em uma sala de aula } \\
\text { regular. }\end{array}$ & $\begin{array}{l}\text { A experiência indicou possibilidades } \\
\text { de trabalhos onde a inclusão significa } \\
\text { muito mais do que uma integração, } \\
\text { em sala de aula, de alunos com } \\
\text { deficiências. }\end{array}$ \\
\hline & & $\begin{array}{l}\text { Santos e Thiengo } \\
\text { (T5) }\end{array}$ & $\begin{array}{l}\text { Discutir os mecanismos utilizados } \\
\text { por um estudante com Síndrome } \\
\text { de Williams para a apropriação do } \\
\text { conceito de números. }\end{array}$ & $\begin{array}{l}\text { Os principais resultados evidenciaram } \\
\text { que que as mediações entre o sujeito, } \\
\text { a pesquisadora e seus colegas, } \\
\text { associadas aos jogos, podem ter } \\
\text { contribuído para o desenvolvimento } \\
\text { cognitivo do estudante com Síndrome } \\
\text { de Williams. }\end{array}$ \\
\hline & & $\begin{array}{l}\text { Mercado e Baraldi } \\
\text { (T8) }\end{array}$ & $\begin{array}{l}\text { Analisar os registros das atividades } \\
\text { matemáticas para estudantes } \\
\text { cegos: da tinta ao Braille. }\end{array}$ & $\begin{array}{l}\text { Os resultados iniciais da pesquisa } \\
\text { indicaram que o bom desenho das } \\
\text { atividades, tanto em Braille como em } \\
\text { tinta, é um ponto importante para a } \\
\text { construção de aulas inclusivas que } \\
\text { permitam o acesso de todos e de todas } \\
\text { ao conhecimento. }\end{array}$ \\
\hline & & $\begin{array}{l}\text { Gomes, Ribeiro e } \\
\text { Mendes (T13) }\end{array}$ & $\begin{array}{l}\text { Relatar a experiência de ensinar } \\
\text { matemática para um estudante } \\
\text { cego congênito por meio da } \\
\text { utilização de recursos didáticos. }\end{array}$ & $\begin{array}{l}\text { A experiência contribuiu para a } \\
\text { formação das docentes bolsistas, bem } \\
\text { como proporcionou uma nova visão } \\
\text { sobre o processo de ensino e de } \\
\text { aprendizagem da matemática. }\end{array}$ \\
\hline & & $\begin{array}{c}\text { Aleixo e } \\
\text { Grützmann (T14) }\end{array}$ & $\begin{array}{l}\text { Investigar como uma aluna com } \\
\text { surdocegueira congênita constrói o } \\
\text { conceito de número. }\end{array}$ & $\begin{array}{l}\text { Os resultados iniciais da pesquisa de } \\
\text { mestrado mostraram que aluna com } \\
\text { surdocegueira realizou com sucesso } \\
\text { as atividades de classificação, } \\
\text { sequenciação, inclusão, portanto } \\
\text { encontra-se em processo de } \\
\text { construção do número. }\end{array}$ \\
\hline & & $\begin{array}{c}\text { Alves, Santos e } \\
\text { Bairral (T15) }\end{array}$ & $\begin{array}{l}\text { Relatar a experiência com } \\
\text { atividade lúdica sobre } \\
\text { combinatória vedando } \\
\text { videntes. }\end{array}$ & $\begin{array}{l}\text { Os resultados mostraram que os } \\
\text { estudantes não aprenderam somente } \\
\text { análise combinatória, mas também } \\
\text { um novo método de ensinar, não só } \\
\text { para alunos videntes, mas para alunos } \\
\text { cegos também. }\end{array}$ \\
\hline & & Dias (T17) & $\begin{array}{l}\text { Relatar uma experiência com } \\
\text { alunos videntes e deficientes } \\
\text { visuais fazendo uso de materiais } \\
\text { grafotáteis. }\end{array}$ & $\begin{array}{l}\text { Os resultados inicias mostraram que } \\
\text { há efetiva participação dos alunos } \\
\text { videntes e deficientes visuais a partir } \\
\text { de práticas educacionais inclusivas. }\end{array}$ \\
\hline & & $\begin{array}{c}\text { Anjos e Moretti } \\
\text { (T19) }\end{array}$ & $\begin{array}{l}\text { Discutir o acesso semiocognitivo } \\
\text { aos objetos do saber matemático } \\
\text { por uma estudante cega. }\end{array}$ & $\begin{array}{l}\text { Os resultados indicaram que tanto a } \\
\text { disciplina de matemática como o } \\
\text { estudante com deficiência são } \\
\text { tratados como diferentes quando }\end{array}$ \\
\hline
\end{tabular}




\begin{tabular}{|c|c|c|c|}
\hline & & & $\begin{array}{l}\text { comparados às demais disciplinas do } \\
\text { currículo escolar ou à organização } \\
\text { social como um todo. }\end{array}$ \\
\hline \multirow{4}{*}{$\begin{array}{c}\text { Recursos } \\
\text { tecnológicos } \\
\text { para o ensino } \\
\text { de Matemática }\end{array}$} & Faustino (T12) & $\begin{array}{l}\text { Investigar cenários inclusivos para } \\
\text { aprendizagem matemática } \\
\text { envolvendo o software GeoGebra. }\end{array}$ & $\begin{array}{l}\text { Os resultados revelaram uma maior } \\
\text { motivação dos envolvidos para } \\
\text { desenvolver as atividades de } \\
\text { matemática utilizando, como } \\
\text { ferramentas, o celular e a cooperação } \\
\text { entre as duplas; a autonomia em parte } \\
\text { da turma; a maior facilidade na } \\
\text { visualização e manipulação das } \\
\text { figuras. }\end{array}$ \\
\hline & $\begin{array}{l}\text { Luna e Esquincalha } \\
\text { (T6) }\end{array}$ & $\begin{array}{l}\text { Contribuir para o desenvolvimento } \\
\text { do campo multiplicativo em alunos } \\
\text { autistas por meio de Tecnologia } \\
\text { Assistiva. }\end{array}$ & $\begin{array}{l}\text { Os resultados parciais da pesquisa de } \\
\text { doutorado evidenciaram a } \\
\text { necessidade de ser explorado o uso de } \\
\text { tecnologia assistiva como ferramenta } \\
\text { de ensino e de aprendizagem de } \\
\text { matemática. }\end{array}$ \\
\hline & $\begin{array}{l}\text { Silva e Vianna } \\
\text { (T16) }\end{array}$ & $\begin{array}{l}\text { Investigar o uso e adequação de } \\
\text { tecnologias assistivas para o } \\
\text { ensino de um conteúdo da } \\
\text { disciplina de Cálculo I junto a um } \\
\text { aluno com deficiência visual } \\
\text { incluído no ensino superior. }\end{array}$ & $\begin{array}{l}\text { Os resultados iniciais da pesquisa de } \\
\text { mestrado buscaram promover e } \\
\text { garantir um ensino e aprendizagem de } \\
\text { qualidade, ao fazer o aluno se sentir } \\
\text { incluído e parte deste processo. }\end{array}$ \\
\hline & Russo e Abar (T4) & $\begin{array}{l}\text { Verificar a contribuição da } \\
\text { plataforma Khan Academy - KA } \\
\text { para a aprendizagem da } \\
\text { matemática de alunos } \\
\text { diagnosticados com Transtorno de } \\
\text { Déficit de Atenção e } \\
\text { Hiperatividade-TDAH. }\end{array}$ & $\begin{array}{l}\text { Os principais resultados indicaram } \\
\text { que as interações com o ambiente da } \\
\text { plataforma permitiram resgatar, } \\
\text { compreender e aprimorar os temas } \\
\text { estudados e contribuíram para a } \\
\text { aprendizagem desses escolares e para } \\
\text { o aprimoramento dos conhecimentos } \\
\text { matemáticos propostos. }\end{array}$ \\
\hline
\end{tabular}

Fonte: Elaborado pelos Autores (2021)

Esses trabalhos evidenciaram, ainda, que tais pesquisas foram realizadas com base na adaptação de tecnologias digitais e recursos didáticos manipuláveis para atender às especificidades dos estudantes com deficiência. Os trabalhos foram alicerçados no paradigma interpretativo dos professores que ensinam Matemática na perspectiva inclusiva, pois eles trazem suas próprias crenças, concepções e experiências para os encontros com as tecnologias digitais e as utilizam para criar seus próprios recursos e serviços, numa inter-relação dinâmica que envolve a participação de ambas as partes na prática pedagógica que se propõe inclusiva. Os resultados indicaram uma diversidade de conteúdos matemáticos representados nos trabalhos como, por exemplo: conceitos geométricos (T2 e T12), Função (T4), Análise Combinatória (T15), dentre outros. Além disso, a prática pedagógica inclusiva indicou que os professores adaptaram e usaram as tecnologias digitais ao ensino de Matemática. Isso nos permite inferir que os resultados representados nos trabalhos apontaram quatro práticas pedagógicas inclusivas:

- Educação Matemática de estudantes com deficiência intelectual (T2, T11);

- Educação Matemática de estudantes com deficiência visual (T1, T8, T13, T14, 
T15, T16, T17, T19);

- Educação Matemática de estudantes com Transtorno do Espectro Autista (T6);

- Educação Matemática de estudantes com Transtorno de Déficit de Atenção e Hiperatividade (T4, T12).

Dessa forma, entendemos que essas quatro práticas pedagógicas inclusivas destacaram as produções dos estudantes com deficiência, explorando o potencial das tecnologias digitais na sala de aula, principalmente quanto à melhoria de desempenho acadêmico de todos os estudantes, uma vez que seu uso pode, de forma planejada pedagogicamente e com metodologia, aumentar a autonomia do estudante na busca de informações e na construção de seu conhecimento ao ter contato com atividades potencialmente inclusivas. Aqui, cabe ao professor conduzir o estudante ao conhecimento implícito na atividade potencialmente inclusiva proposta em sala de aula, ou seja, o papel do professor torna-se fundamental para a promoção da aprendizagem (GARCIA et al., 2020).

\subsection{Tecnologias digitais e recursos didáticos manipuláveis para o ensino de Matemática na perspectiva da criação}

A análise dos trabalhos que compõem o corpus da pesquisa possibilitou identificar seis trabalhos - T3, T7, T9, T10, T18 e T20 —, que constituem essa categoria e indicam características relacionadas à criação de tecnologias digitais e recursos didáticos manipuláveis no ensino de Matemática, as quais tornaram possível destacar duas abordagens relacionadas à Educação Matemática Inclusiva, a saber: a) recursos didáticos para o ensino de Matemática; b) estratégias pedagógicas para o ensino de Matemática.

Entre os trabalhos que discutiram atividades pedagógicas para o ensino de Matemática, destacamos a pesquisa desenvolvida por Santos e Borba (T10). As autoras analisaram a compreensão de conceitos de probabilidade por um estudante cego, a partir de intervenções didáticas relacionadas ao conteúdo de Genética, envolvendo a probabilidade de eventos sucessivos. Os aportes teóricos utilizados foram de Vygotsky (1997), para compreender a aprendizagem de estudantes com deficiência, e o cenário proposto por Fernandes (2017) para a aprendizagem. Entre os resultados obtidos, as autoras indicaram que os recursos didáticos manipulativos - por exemplo, caixa de ovos, 
cubos, esferas -, que funcionaram como "ferramentas mediadoras com essas características e adequadas às diferentes tarefas nem sempre é possível, precisando, assim, construí-las" (SANTOS e BORBA, T10, p. 9). Concluíram que a construção de recursos didáticos manipulativos deve ser pensada simultaneamente na singularidade e coletividade de todos os estudantes, independentemente de suas especificidades.

Ainda, tendo como alvo as estratégias pedagógicas para o ensino de Matemática, as pesquisas de Silva e Costa (T7) e Silva e Carvalho (T20) apresentaram como cerne a construção de recursos didáticos que contribuem nos processos de ensino e de aprendizagem de Matemática. Entretanto, a principal distinção foi a seguinte: o estudo realizado por Silva e Costa (T7), em fase inicial, tinha como objetivo construir recursos pedagógicos para estudantes surdos e investigar quais conteúdos matemáticos podem ser mais adequados ao ensino a partir dos recursos construídos. Já na pesquisa de Silva e Carvalho (T20), também em fase inicial, os autores objetivaram propiciar reflexões sobre a relevância da tecnologia para a interpretação de gráficos por estudantes cegos, buscando fazer com que os estudantes cegos do ensino básico usassem os gráficos táteis elaborados para fazer atividades de proporcionalidade direta e inversa.

Silva e Costa (T7) e Silva e Carvalho (T20) concordaram que o uso de recursos didáticos para a prática pedagógica inclusiva pode ser visto como uma escolha metodológica auxiliar ao trabalho docente, oportunizando para todos, em seus diferentes contextos de aprendizagem, o acesso ao conhecimento matemático e realizando as atividades com maior autonomia. Destacaram, porém, que, para isso, o professor, seja da sala de Atendimento Educacional Especializado ou da sala de aula regular, deve se envolver na prática pedagógica, isto é, planejar aulas atrativas e prazerosas para seus alunos, apresentando atividades potencialmente inclusivas (CARVALHO, 2018).

Uma segunda abordagem abrangeu as estratégias pedagógicas para o ensino de Matemática, apresentadas a partir de diferentes propostas. Em uma delas, Milli e Thiengo (T3) analisaram a apropriação da representação numérica e da quantificação por um estudante com deficiência intelectual, utilizando o recurso tampimática como estratégia didática. Segundo os autores, "o tampimática é um material manipulável, constituído por uma coleção de tampinhas e acessórios que auxiliam as práticas de manipulação durante as atividades" (MILLI e THIENGO, T3, p. 2). 
Para alcançar os objetivos supracitados, Milli e Thiengo (T3) optaram por desenvolver uma pesquisa aliada à observação livre, discutida por Triviños (2017). Para tanto, utilizaram o método desenvolvido por Vygotsky (1996), denominado "método funcional da estimulação dupla". Dentre os resultados, os autores mencionaram que as experiências matemáticas oriundas das relações sociais permitem que os processos compensatórios contribuam para superar as dificuldades relacionadas à deficiência. Os recursos didáticos manipuláveis funcionaram como meios auxiliares, ou seja, o uso da fala, os gestos, as atividades escritas e os objetos cooperaram com o processo de compensação para desenvolver o pensamento aritmético do estudante com deficiência. Kaleff (2016, p. 59) pontua "ser auxiliar para a abstração matemática, ou seja, proporcionar ajuda para fundamentar e facilitar um caminho ao raciocínio abstrato lógicodedutivo".

Os trabalhos de Madalena e Souza (T9) e Silva e Barros (T18) apresentaram como convergência a construção de tecnologias digitais que proporcionassem uma aprendizagem mais adequada ao ensino de Matemática para estudantes surdos, no entanto divergiram quanto à estratégia pedagógica. Por exemplo, Madalena e Souza (T9) criaram estratégias visando auxiliar na construção da noção de tempo de crianças surdas, usuárias da Língua Brasileira de Sinais (Libras), argumentando que o uso coletivo do mural da sala de aula, por todos os estudantes, possibilita a identificação do dia da semana e do dia do mês, de forma que "os estudantes vejam uns aos outros para que haja a troca de informação entre eles, assim, estas atividades costumavam ocorrer com todos os alunos sentados em semicírculo diante do mural” (MADALENA e SOUZA, T9, p. 8).

Silva e Barros (T18) elaboraram estratégias de ensino na perspectiva de metodologia de projetos, buscando identificar pares ordenados no plano cartesiano, construídos por uma estudante surda, divididas em dois momentos: no primeiro, a construção do plano cartesiano e, no segundo, a identificação dos pares ordenados no plano cartesiano. Os resultados apresentados pelos autores indicaram, entre outros aspectos, que entre os estudantes que participaram regularmente dos projetos, era notório o progresso tanto acadêmico, na compreensão de conceitos matemáticos, quanto social, havendo, assim, uma melhora na autoestima dos aprendizes.

Em suma, esses dois trabalhos apontaram para a necessidade do desenvolvimento 
de estratégias pedagógicas diversificadas que atendessem a todos os estudantes na sala de aula, favorecendo o desenvolvimento de habilidades e competências atreladas à formação humana, intelectual e social de todos. Para isso, torna-se necessário "o uso e a construção de recursos, além de revisões contínuas dos assuntos interligados à matéria dada em sala de aula, são meios de contribuir na inserção desses alunos na escola regular" (SILVA e BARROS, T18, p. 1).

Diante dos trabalhos elencados nesta categoria, sistematizados no Quadro 3, podemos verificar a relevância atribuída pelos pesquisadores às atividades pedagógicas para o ensino de Matemática (SILVA e COSTA, T7; SANTOS e BORBA, T10; SILVA e CARVALHO, T20) e às estratégias pedagógicas para o ensino desta disciplina (MILLI e THIENGO, T3; MADALENA e SOUZA, T9; SILVA e BARROS, T18). Os resultados representados nos trabalhos apontaram três práticas pedagógicas inclusivas:

- Educação Matemática de estudantes com deficiência intelectual (T3);

- Educação Matemática de estudantes com deficiência auditiva (T7, T9, T18);

- Educação Matemática de estudantes com deficiência visual (T10, T20).

De modo geral, os artigos apontaram resultados de pesquisas que tratam de atividades pedagógicas e estratégias pedagógicas que podem auxiliar na promoção da Educação Matemática Inclusiva, na/para formação inicial e/ou continuada de professores que ensinam Matemática. Entretanto, há necessidade de adequação nos cursos de formação inicial e/ou continuada para professores, em especial da área de Matemática, na construção do saber docente para o uso das tecnologias digitais (GARCIA et al., 2020). Nesse sentido, segundo Richit (2016, p. 110),

\footnotetext{
a formação do professor precisa propiciar-lhe embasamento e vivências que lhe dê condições de promover novas práticas. Em outras palavras, o professor, em seu processo de formação, precisa vivenciar diferentes tendências no ensino da Matemática, por meio das quais constitua as bases da sua prática docente em sala de aula, prática essa comprometida com a apropriação de conhecimentos por parte do estudante.
}

Desse modo, Castro (2018, p. 44) aponta que estas adequações nos cursos demandam mudanças, "tais como as alterações curriculares e a criação de ambientes propícios à reflexão, discussão e avaliação acerca dessa temática". Corroborando com o autor, Nogueira (2019, p. 8) acrescenta que, para legitimar as diferenças e não fazê-las 
desaparecer, torna-se necessária e urgente "a adoção de currículos diferenciados e diferentes práticas pedagógicas em vigor em uma mesma sala de aula, para que todos os alunos possam acessar o objeto de conhecimento". Assim, os processos de formação continuada "precisam promover contextos investigativos e desafiadores que preparem e motivem os docentes a promover novas práticas, utilizando diferentes recursos, sobretudo as tecnologias digitais" (RICHIT, 2016, p. 117).

Considerando as pesquisas relacionadas às tecnologias digitais e recursos didáticos manipuláveis na Educação Matemática Inclusiva, trazemos, no Quadro 3, uma síntese dos trabalhos enquadrados nesta categoria, bem como as duas subcategorias temáticas.

Quadro 3: Síntese dos trabalhos relacionados à segunda categoria

\begin{tabular}{|c|c|c|c|c|}
\hline Categoria & Subcategoria & Autor & Objetivo & Principais resultados \\
\hline \multirow{6}{*}{$\begin{array}{l}\text { Tecnologias } \\
\text { Digitais } \\
\text { para o } \\
\text { ensino de } \\
\text { Matemática } \\
\text { na } \\
\text { perspectiva } \\
\text { da criação }\end{array}$} & \multirow{3}{*}{$\begin{array}{l}\text { Recursos } \\
\text { didáticos para } \\
\text { o ensino de } \\
\text { Matemática }\end{array}$} & $\begin{array}{l}\text { Silva e Costa } \\
\text { (T7) }\end{array}$ & $\begin{array}{l}\text { Construir materiais pedagógicos } \\
\text { que proporcionem uma } \\
\text { aprendizagem mais adequada aos } \\
\text { surdos no ensino de matemática. }\end{array}$ & $\begin{array}{l}\text { O trabalho apresenta resultados iniciais do } \\
\text { projeto de Iniciação Científica que visa entregar } \\
\text { os materiais construídos ao Centro de } \\
\text { Atendimento Especializado na área da Surdez - } \\
\text { CAES, da cidade de Marabá-PA, para subsidiar a } \\
\text { organização de um laboratório de materiais } \\
\text { didáticos para o ensino de Matemática a alunos } \\
\text { surdos. }\end{array}$ \\
\hline & & $\begin{array}{c}\text { Santos e } \\
\text { Borba }(\mathrm{T} 10)\end{array}$ & $\begin{array}{l}\text { Analisar a compreensão de } \\
\text { conceitos de probabilidade por } \\
\text { um estudante cego a partir de } \\
\text { intervenções didáticas. }\end{array}$ & $\begin{array}{l}\text { A pesquisa apresenta resultados parciais de uma } \\
\text { tese de doutorado que visa contribuir com o } \\
\text { desenvolvimento de conceitos probabilísticos do } \\
\text { estudante cego e outros videntes a partir de } \\
\text { intervenções didáticas. }\end{array}$ \\
\hline & & $\begin{array}{l}\text { Silva e } \\
\text { Carvalho } \\
\text { (T20) }\end{array}$ & $\begin{array}{l}\text { Analisar a interpretação de } \\
\text { gráficos que apresentam relações } \\
\text { de proporcionalidade direta e } \\
\text { inversa por estudantes cegos. }\end{array}$ & $\begin{array}{l}\text { A pesquisa apresenta resultados iniciais de uma } \\
\text { tese de doutorado que visa ampliar a discussão } \\
\text { sobre a relevância da tecnologia assistiva para a } \\
\text { interpretação de gráficos por estudantes cegos. }\end{array}$ \\
\hline & \multirow{3}{*}{$\begin{array}{l}\text { Estratégias } \\
\text { pedagógicas } \\
\text { para o ensino } \\
\text { de } \\
\text { Matemática }\end{array}$} & $\begin{array}{l}\text { Milli e } \\
\text { Thiengo } \\
\text { (T3) }\end{array}$ & $\begin{array}{l}\text { Analisar a apropriação da } \\
\text { representação numérica e da } \\
\text { quantificação por um aluno com } \\
\text { deficiência intelectual utilizando } \\
\text { o Tampimática. }\end{array}$ & $\begin{array}{l}\text { A pesquisa apresenta resultados de um trabalho } \\
\text { de mestrado que discute a contribuição das } \\
\text { relações sociais nos processos compensatórios } \\
\text { para superação das dificuldades relacionadas à } \\
\text { deficiência intelectual. }\end{array}$ \\
\hline & & $\begin{array}{l}\text { Madalena e } \\
\text { Souza (T9) }\end{array}$ & $\begin{array}{l}\text { Apresentar estratégias que visem } \\
\text { auxiliar na construção da noção } \\
\text { de tempo de crianças surdas, } \\
\text { usuárias da Língua Brasileira de } \\
\text { Sinais (Libras). }\end{array}$ & $\begin{array}{l}\text { Os resultados mostram que a falta de } \\
\text { entendimento inicial das crianças com relação à } \\
\text { compreensão dos marcadores de tempo (dia, mês } \\
\text { e ano) ocorreu, principalmente, pelas } \\
\text { dificuldades socioculturais que uma criança } \\
\text { surda enfrenta diante de uma sociedade, } \\
\text { majoritariamente, ouvinte. }\end{array}$ \\
\hline & & $\begin{array}{c}\text { Silva e } \\
\text { Barros (T18) }\end{array}$ & \begin{tabular}{llr} 
Auxiliar na & \multicolumn{2}{l}{ aprendizagem de } \\
Matemática & de alunos com \\
deficiência & por meio de \\
atividades. & &
\end{tabular} & $\begin{array}{l}\text { Os principias resultados mostraram uma maior } \\
\text { compreensão de conceitos matemáticos. }\end{array}$ \\
\hline
\end{tabular}

Fonte: Elaborado pelos Autores (2021)

Nestes casos, evidenciamos que os seis trabalhos indicaram o uso das tecnologias digitais e recursos didáticos manipuláveis por professores para o desenvolvimento do 
conteúdo ou conceito matemático, por exemplo: conceito aritmético (T3) e probabilístico (T10), conteúdo de Estatística (T20) apontando que pesquisas com esse viés estão preocupadas com a criação de recursos e serviços para auxiliar estudantes a escrever textos, mediados pelo uso dos recursos digitais, de modo a alcançar maior clareza da atividade proposta e orientação mais próxima para o professor no esclarecimento de dúvidas, ou seja, vê-los como instrumentos potenciais para a mudança no ensino. Tal posicionamento, para Felcher, Pinto e Folmer (2020) e Borba, Almeida e Chiari (2015), indica que o uso das tecnologias digitais é passível de contribuir para modificar a realidade do ensino e da aprendizagem da Matemática para estudantes com deficiência, podendo ser um recurso para minimizar as dificuldades enfrentadas pelos estudantes na aprendizagem de conteúdos matemáticos.

Nesse sentido, Moran, Masseto e Beherens (2008) citam a necessidade de integrar tecnologias, metodologias, estratégias e atividades inclusivas, aproximando as diferentes mídias, trazendo para a sala de aula recursos audiovisuais e sensíveis para atender a todos e, assim, variar a forma de conduzir a aula. Bessa (2006, p. 51), nesse sentido, aduz que "as diferentes mídias com diferentes códigos e linguagens geram sentimentos distintos, portanto, possibilitam significar diferente".

De modo geral, percebemos que, embora os trabalhos aqui mapeados agreguem uma diversidade de campos teóricos e metodológicos, por exemplo, Santos e Borba (T10), Silva e Carvalho (T20), a maioria se apoia na teoria histórico-cultural de Vygotsky (1996, 1997) para os processos de ensino e de aprendizagem de pessoas com deficiência. Além disso, as análises aqui discutidas evidenciam a lacuna existente de trabalhos relacionados à formação continuada para o uso das tecnologias digitais e/ou recursos didáticos manipuláveis no ensino de Matemática para estudantes com deficiência, contexto que exige maior atenção e, assim, subsidia pesquisas futuras da área. Com isso, "é preciso refletir sobre a formação inicial de professores e passar a ensinar por meio de recursos digitais e desenvolver práticas que permitam compreender como utilizar, como ensinar e quais metodologias de ensino aliar a esses recursos" (PERIPOLLI, XAVIER e NUNES, 2020, p. 7). Portanto, apesar de os trabalhos do corpus serem independentes, com diferentes perspectivas teórico-metodológicas e focos temáticos, compactuaram no sentido de responder ao objetivo desta pesquisa, de identificar e compreender, nas comunicações científicas dos anais do I Encontro Nacional de Educação Matemática 
Inclusiva, temáticas sobre o uso de tecnologias digitais.

\section{Conclusão e implicações}

O presente estudo teve como propósito analisar a produção do conhecimento, representado nas comunicações científicas, referentes ao uso das tecnologias digitais e recursos didáticos na prática pedagógica, nos anais do I Encontro Nacional de Educação Matemática Inclusiva (I ENEMI) realizado em 2019.

No intuito de orientar e esclarecer esta apresentação e discussão dos resultados, foram apresentadas as seguintes categorias: tecnologias digitais e recursos didáticos manipuláveis para o ensino de Matemática na perspectiva da adaptação, e tecnologias digitais e recursos didáticos manipuláveis para o ensino de Matemática na perspectiva da criação.

Nessas categorias, foram agrupados os trabalhos comuns observados nos dados que indicam como os professores utilizam as tecnologias digitais e recursos didáticos manipuláveis nas práticas pedagógicas. Esses usos referem-se às decisões dos professores ao implementar os recursos em sala de aula, a partir do contato com tecnologias e metodologias.

Em relação à primeira categoria, percebemos que os(as) professores(as) fizeram uso das tecnologias digitais e recursos didáticos na prática pedagógica inclusiva, adaptando tais tecnologias e recursos e que, para isso ocorresse, os profissionais deveriam se aproximar, ao máximo, de todos os contextos em que os estudantes com deficiência estivessem inseridos. Na segunda categoria, evidenciamos outro tipo de uso das tecnologias digitais: criando tecnologias digitais e recursos didáticos. Isso possibilita aos profissionais trazerem suas próprias crenças, concepções e experiências para os encontros com as tecnologias digitais e criarem seus próprios significados, ou seja, eles interpretam as intenções pretendidas para desenvolver o conteúdo matemático para todos os estudantes. Ao identificarmos tais usos na prática pedagógica inclusiva, entendemos que o professor ensina por meio das tecnologias digitais, seja adaptando ou criando TD na/para a prática pedagógica.

Sendo assim, não pretendemos esgotar a discussão acerca do uso das tecnologias digitais por professores(as), na implementação de atividades de Matemática na prática 
pedagógica inclusiva, já que apontamos a lacuna na formação de professores que ensinam Matemática na perspectiva inclusiva para uso de tecnologias. Desse modo, estudos posteriores serão realizados, e estão em andamento, a fim de aprofundar a análise das práticas pedagógicas com tecnologias digitais ocorridas em distintos contextos escolares inclusivos.

Como implicações deste artigo, uma questão que pode ser produtivamente explorada em futuras pesquisas é a seguinte: Como as tecnologias digitais, em especial, concorrem para reconfigurar e/ou reorganizar a pesquisa em Educação Matemática Inclusiva sob o ponto de vista da metodologia?

\section{Referências}

BALADELI, Ana Paula Domingos. Desafios na formação do professor para o uso de tecnologias de informação e comunicação no ensino e na aprendizagem de Língua Inglesa. 2009. 125 f. Dissertação (Mestrado em Educação) — Universidade Estadual de Maringá. Maringá.

BARDIN, Laurence. Análise de conteúdo. Tradução de Luís Antero Reto e de Augusto Pinheiro. Lisboa: Edições 70, 2009.

BERNSTEIN, Basil. Class, codes and control: the structuring of pedagogic discourse. London: Routledge, 1990.

BESSA, Dante Diniz. Teorias da comunicação. Brasília: UnB, 2006.

BORBA, Marcelo de Carvalho; ALMEIDA, Helber Rangel Formiga Leite de; CHIARI, Aparecida Santana de Souza. Tecnologias digitais e a relação entre teoria e prática: uma análise da produção em trinta anos de BOLEMA. Bolema, Rio Claro, v. 29, n. 53, p. 11151140, dez. 2015.

CARVALHO, Carla Cristina Coelho. Laboratório de recursos didáticos como intervenções para o ensino de matemática para alunos surdos. 2018. 73f. Trabalho de Conclusão de Curso (Licenciatura em Matemática) - Universidade Federal do Sul e Sudeste do Pará. Santana do Araguaia.

CARVALHO, Rodrigo Lacerda; CASTRO FILHO, José Aires de; FERREIRA, Luis David Bonfim. O campo multiplicativo na formação inicial de professores de Matemática com suporte das tecnologias digitais. Educação Matemática Debate, Montes Claros, v. 1, n. 3, p. 1-20, set./dez. 2017.

CASTRO, Anna Luisa de. Matemática e o currículo da era digital: os desafios para a inovação na prática educativa. 2018. 291f. Tese (Doutorado em Educação para a Ciência) — Faculdade de Ciências. Universidade Estadual Paulista. Bauru. 
FELCHER, Carla Denize Ott; PINTO, Ana Cristina Medina; FOLMER, Vanderlei. Tendências em tecnologias digitais no ensino da Matemática reveladas no EBRAPEM. Educação Matemática Pesquisa, São Paulo, v. 21, n. 2, p. 1-22, maio/ago. 2019.

FERNANDES, Solange Hassan Ahmad Ali. Educação matemática inclusiva: adaptação $\times$ construção. Revista Educação Inclusiva, Campina Grande, v. 1, n. 1, p.78-95, jul./dez. 2017.

GARCIA, Fernando Oliveira; PEREIRA, Caroline Subirá; FRASSON, Antonio Carlos; SALLES, Virginia Ostroski. Tecnologias móveis na formação inicial do professor de Matemática. Educação Matemática Pesquisa, São Paulo, v. 22, n. 1, p. 214-230, jan./abr. 2020.

GIL, Antônio Carlos. Como elaborar projetos de pesquisa. 4. ed. São Paulo: Atlas, 2007.

GOEDERT, Lidiane; BORGES, Martha Kaschny. Comunicação mediada por TIC: saberes, colaboração e conflito na aprendizagem online. In: COLÓQUIO DA AFIRSE, 23, 2016, Lisboa. Atas da XXIII AFIRSE: As pedagogias na sociedade contemporânea: desafios às escolas e aos educadores. Lisboa: AFIRSE, 2016, p. 1-10.

KALEFF, Ana Maria Martensen Roland. Aprendizagem significativa criativa em ambiente de laboratório de ensino. In: KALEFF, Ana Maria Martensen Roland. (Org.). Vendo com as mãos, olhos e mente: recursos didáticos para laboratório e museu de educação matemática inclusiva do aluno com deficiência visual. Niterói: CEAD/UFF, 2016, p. 52-62.

KENSKI, Vani Moreira. Educação e tecnologias: o novo ritmo da informação. 8. ed. Campinas: Papirus, 2012.

LORENZATO, Sérgio. (Org). O laboratório de ensino de Matemática na formação de professores. 3. ed. Campinas: Autores Associados, 2010.

MORAN, José Manuel; MASSETO, Marcos Tarciso; BEHRENS, Marilda Aparecida. Novas tecnologias e mediação pedagógica. 14. ed. São Paulo: Papirus, 2008.

MOURA, Patrícia de Souza; LAVOR, Otávio Paulino. Uso de objetos de aprendizagem no ensino da Lei dos Senos e da Lei dos Cossenos. Educação Matemática Debate, Montes Claros, v. 5, n. 11, p. 1-15, 2021.

NOGUEIRA, Clélia Maria Ignátius. Educação matemática e educação especial na perspectiva inclusiva: educação matemática inclusiva? In: ENCONTRO NACIONAL DE EDUCAÇÃO MATEMÁTICA, 13, 2019, Cuiabá. Anais do XIII ENEM: Educação Matemática com as Escolas da Educação Básica: interfaces entre pesquisas e salas de aula. Cuiabá: SBEM, 2019, p. 1-14.

PERIPOLLI, Patrícia Zanon; XAVIER, Patrícia Cristiane da Cunha; NUNES, Janile Fernandes. Recursos digitais e aprendizagem por pares: da formação de professores de Matemática em período de pandemia. Em Teia, Recife, v. 11, n. 2, p. 1-17, maio/ago. 2020 . 
PLETSCH, Márcia Denise. A formação de professores para a educação inclusiva: legislação, diretrizes políticas e resultados de pesquisas. Educação em Revista, Curitiba, n. 33, p. 143-156, 2009.

RAMIREZ, Alejandro Rafael Garcia; MASUTTI, Mara Lúcia. A educação de surdos em uma perspectiva bilíngue: uma experiência de elaboração de software e suas implicações pedagógicas. Florianópolis: EdUFSC, 2009.

RICHIT, Adriana. Interfaces entre as tecnologias digitais e a resolução de problemas na perspectiva da Educação Matemática. Revista de Matemática, Ensino e Cultura, Belém, v. 11, n. 21, p. 109-122, jan./abr. 2016.

ROSA, Paulo Ricardo da Silva. Uma introdução à pesquisa qualitativa em Ensino de Ciências. Campo Grande: EdUFMS, 2013.

SANTOS, Flávio Lopes dos; CORDEIRO, Janivaldo Pacheco; GOLÇALVES, Nahun Thiaghor Lippaus Pires; THIENGO, Edmar Reis. Contribuições da tecnologia na construção de uma educação inclusiva: o trabalho com um aluno deficiente visual nas aulas de matemática. Educação Matemática Debate, Montes Claros, v. 1, n. 2, maio/ago. p. 131-153, 2017.

SILVA, Andressa da Costa Manholer; FREITAG, Isabela Hrecek; TOMASELLI, Maria Vitória Ferro; BARBOSA, Carmem Patrícia. A importância dos recursos didáticos para o processo de ensino-aprendizagem. Arquivos do MUDI, Maringá, v. 21, n. 2, p. 20-31, maio/ago. 2017.

SOUSA, Thiago Weslei de Almeida; QUEIRÓS, Wellington Pereira. Panorama das pesquisas sobre a análise de recursos didáticos no Encontro Nacional de Pesquisa em Educação em Ciência (ENPEC). Amazônia, Belém, v. 15, n. 34, p.165-177, jul./dez. 2019.

TRIVIÑOS, Augusto Nibaldo Silva. Introdução à pesquisa em Ciências Sociais: a pesquisa qualitativa em Educação. 7. ed. São Paulo: Atlas, 2017.

VYGOTSKY, Lev Semionovitch. A formação social da mente: o desenvolvimento dos processos psicológicos superiores. Tradução de José Cipolla Neto. 7. ed. São Paulo: Martins Fontes, 1996.

VYGOTSKY, Lev Semionovitch. Fundamentos de defectología. Obras Completas, tomo V. Tradición de Maria del Carmen Ponce Fernandez. Havana: Editorial Pueblo y Educación, 1997.

VYGOTSKY, Lev Semionovitch. Psicologia pedagógica. Tradução de Paulo Bezerra. 3. ed. São Paulo: WMF, Martins Fontes, 2010. 